\title{
The use of geographical informational systems in modern agriculture
}

\author{
Stefan Ghimisi ${ }^{1}$ \\ ${ }^{1}$ Constantin Brâncuși University of targu Jiu, România \\ E-mail:ssghimisi@gmail.com
}

\begin{abstract}
Precision agriculture is a subsystem of sustainable and ecological agriculture systems, but also for the intensive agriculture system. The main factors serving precision agriculture are the increase in soil variation combined with the advent of technologies such as global satellite navigation systems, geographic information systems and microcomputers. In recent years, farmers have gained access to new technologies through the use of GPS-Global Positioning System and Decision Support Systems, which were previously a monopoly of the military arsenal, are now new computerized technologies in the modern civilian world.
\end{abstract}

Keywords: precision agriculture, GPS, GIS

\section{Introduction}

Precision agriculture uses advanced technologies to carry out agricultural works, but it cannot characterize the ensemble formed by an agricultural system in its own right. Precision agriculture is a subsystem of sustainable and ecological agriculture systems, but also for the intensive agriculture system. $[1,2,3,5]$

Therefore, due to the use of information and technology, the following can be achieved:

monitoring the works on each plot;

guidance or self-guidance in the field;

$\square$ precision for the executed works

Precision agriculture includes a set of technologies that combine sensors, information systems, modern machines and high-performance management to increase the production obtained.

In the future, in order to ensure the supply of food, adequate and quality quantities are required, in addition the ability to monitor food products in productions through processing, storage and retail offers the opportunity to respond to changing market conditions, to provide food for a correct and healthy nutrition.

Precision agriculture emerged in the mid-1980s as a way to apply the correct treatment to the right place at the right time.

The main factors serving precision agriculture are the increase in soil variation combined with the advent of technologies such as global satellite navigation systems, geographic information systems and microcomputers. [11]

Components of precision agriculture[4,6]

Simulation models, decision support systems (DSS) and geographic informatics system (GIS);

Remote sensing and global positioning system (GPS);

Production maps and precision application of chemicals. 
Precision agriculture aims to optimize the use of soil, water and chemical inputs (fertilizers and pesticides) on specific local bases and has as objectives: [13]

Obtaining large and quality productions;

Optimizing profits;

Full realization of environmental protection;

Increasing the durability of agricultural systems;

Reduction of the production price per unit of product.

\section{Geographic informational systems used in agriculture}

Global Positioning System (GPS) it's a satellite navigation system that can provide the exact position on the globe, how to get to a place, how fast they're moving, where they've been, how far they've come, what time it is, and more.

The GPS was originally designed to help the U.S. military with the precise location of military, vehicles, planes and ships around the world. The GPS system (figure 1) consists of three segments: Space, Control and User.

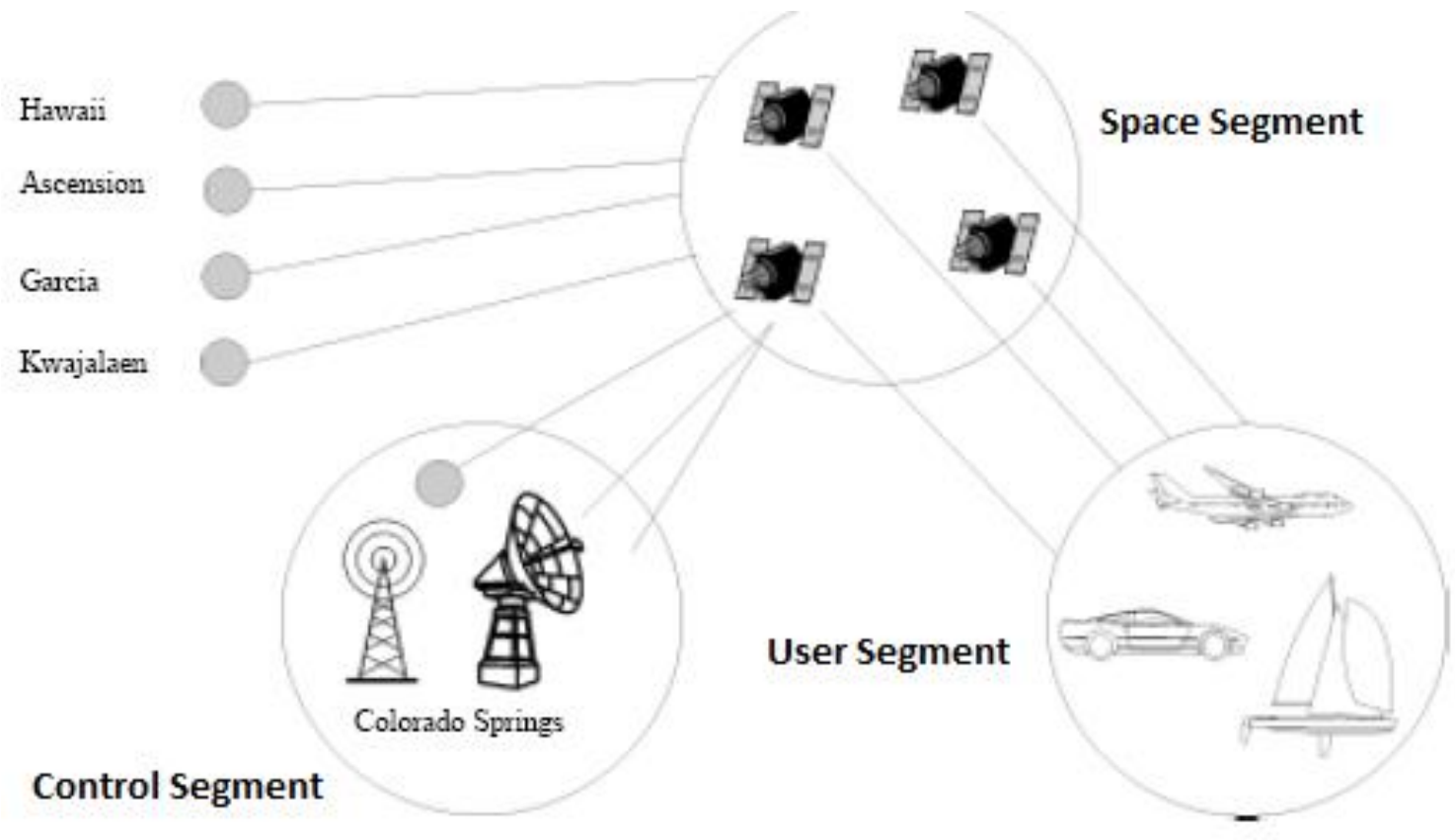

Figure 1 The components of the GPS system

How does a GPS determine a position[7,8]:

When a GPS receiver is turned on for the first time, download information from all satellites. This process, the first time, can take up to 12 minutes; but once this information is downloaded, it is stored in his memory for future use.

The GPS receiver calculates the distance from each satellite to the receiver using the formula: distance $=$ speed $\mathrm{x}$ time. The receiver determines the position using triangulation. When receiving signals from at least three satellites a receiver should be able to calculate the approximate position. The receiver needs at least four or more satellites to calculate a more accurate position. The position can be reported in latitude/longitude, UTM, or other coordinate systems.

Geographical Information System (GIS) is a computer-based tool for mapping and analyzing spatial data. These skills differentiate GIS from other information systems and make it useful to a wide range of public and private activities to explain events, predict results, and plan strategies. 
Many have characterized GIS as one of the most powerful technologies because it focuses on integrating knowledge from multiple sources.

The GIS components are:

Hardware: The hardware component includes the computer on which a GIS operates, the monitor on which the results are displayed, and a printer to make copies of the results.

Software: GIS software provides the functions and tools needed to store, analyze, and display geographic information.

Data: They are the most important component of the GIS system. A GIS will integrate spatial data with other data resources and can use database management systems.

Methods: A successful GIS works according to a well-designed plan and a set of rules unique in each organization

Differences between GPS and GIS:

GPS is a satellite system that designs information for GPS receivers in the field, while GIS is a software program that allows users to store and manipulate large amounts of data from GPS and other sources.

\section{The use of GPS and GIS in agriculture[9]}

The use of GPS and GIS in agriculture is growing rapidly. Among their use, we can mention:

Soil sampling: soil sampling can be organized with the help of GPS and a mapping software. The sample locations can be intermediate points marked on the mapping software. Then when the lab results are returned the data can be represented on the maps. Location information can save money and time, allowing only those areas in need to be handled.

Tractor guidance: Farmers can put tractors on autopilot. When you show a surface a GPS record is made and then the tractor can be programmed to follow the same route for cultivation, fertilization, pest control and harvesting.

Pest control: A GPS can be used to record locations with insect-related problems. The data can then be used by the driver to selectively target problem areas instead of treating an entire field. This method saves time, fuel and insecticide.

Animal tracking: The position of valuable animals on a large farm can be monitored by GPS transmitters attached to the necks of animals.

Crop yield: Estimates of yield changes on a property can be made using GPS. To do this a property is divided into zones and the yield of each zone is estimated and represented on a map. The map can then be used for decision-making regarding the next culture

GIS gives farmers the opportunity to increase production, reduce production costs, and manage crops as efficiently as possible.

GIS can make a difference in agricultural production by:

Reducing agricultural production costs, such as fertilizers, fuel, seeds, labour.

For insurance companies - risk assessment

Because of the financial risks involved in agricultural production, farmers usually provide crops and animals with potential physical risks, such as hail, frost, drought, and disease.

Insurance companies calculate the cost of insurance based on risk assessment tables, which are developed by insurers. Factors that are taken into account in determining the insurance rate include physical risks as well as the history of a plot of specific land

Pest control and control

Agricultural pest control is based on accurate data on the amount and place with pests or other infestations in a specific area GIS plays an important role in data collection, interpolation, and analysis.

Data can be:

-Gathered in very short time using mobile GIS.

-Analyzed in the farm office with desktop GIS.

This process of data collection, analysis, and processing provides farmers with current information on pest locations, potential risk areas, and recommendations for control.

Monitoring of agricultural areas (Figure 2) 
Using mobile GIS technology, farmers can measure, record, and land characteristics for: nutrient deficiencies and water consumption during regular inspections.

When collecting data in this area, remedial measures can be developed and implemented quickly. In the office, the recently collected data can only be extracted for a specific field, crop, or pest.

Optional equipment, such as digital cameras and GPS devices, can be easily added to a mobile GIS for improved data collection.

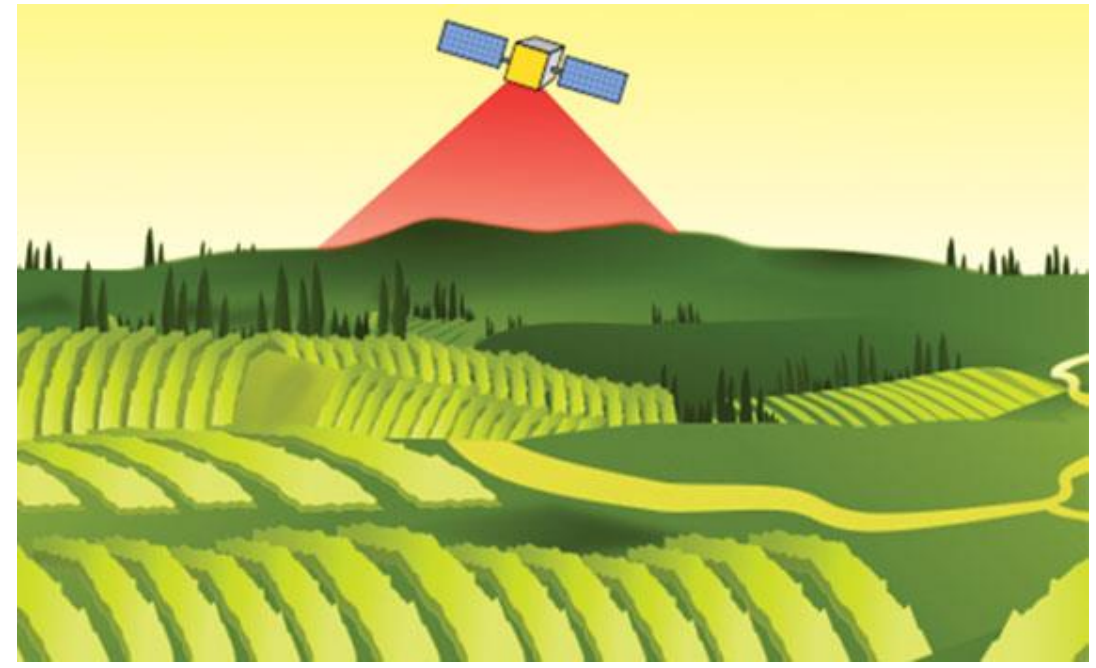

Figure 2.Monitoring of agricultural areas

\section{Precision agriculture}

Information technology has had a substantial impact on agriculture, in particular through the use of global positioning systems (GPS) in combination with GIS tools.

Potentially, the factors that influence crop productivity can be identified, mapped, and used to provide an implemented solution. Precision agriculture paves the way to better manage the variations in which previously, in terms of treatments, a field was normally assumed to be homogeneous.

Precision agriculture uses spatial databases within field, environmental and management variables in order to maximize production across the entire field.

\section{Water resource management}

GIS is a familiar tool for managing water resources for agricultural and conservation purposes.

It can help establish water rights for farmers and support applications for drilling permission for irrigation.

It can also be used to observe water loss from the soil through drainage and unshackled channels, help and determine profitability, and prioritize projects of irrigation canals.

\section{Technical systems used in precision agriculture}

In recent years, farmers have gained access to new technologies through the use of GPS-Global Positioning System and Decision Support Systems, which were previously a monopoly of the military arsenal, are now new computerized technologies in the modern civilian world. [10]

\section{Sensors for automatic measurements}

Scientists and equipment manufacturers are trying to modify existing laboratory methods and develop indirect measurement techniques that could quickly allow soil mapping.

Sensors can be:

- Electromagnetics;

- Optics;

- Mechanics;

- Acoustics. 
Electromagnetic sensors use electrical circuits to measure the ability of soil particles to conduct or accumulate electric charge.

When these sensors are used, the ground becomes part of an electromagnetic circuit and the change in local conditions immediately affects the signal recorded by a data logger.

The electromagnetic properties of the soil are largely influenced by soil texture, salinity, organic matter and moisture. In some cases other soil properties such as nitrate concentration or $\mathbf{p H}$ can be determined with this type of sensors.

Optical sensors use light reflection to characterize a particular type of soil. Vehicles based on optical sensors use the same technical principle as in the case of remote sensing. Optical sensors have been developed to perform soil mapping to different depths.

Mechanical sensors can be used to estimate the mechanical strength of the soil (sometimes relevant in the case of compaction). These sensors use a mechanism that penetrates or cuts the ground and records the force measured by transducers or load cells.

Electrochemical sensors provide the most important information about the concentration of nutrients in soil and $\mathrm{pH}$ within precision agriculture. [15]

From the measurement mode point of view:

- Contact sensors

- Distance sensors

From the point of view of the measurement target:

- Sensors for monitoring the condition of cultures

- Climate sensors

- Sensors for soil monitoring

Chlorophyll SPAD meter and HNT(Figure 3) - portable device for measuring chlorophyll at wavelengths of $650 \mathrm{~nm}$ (red) and $940 \mathrm{~nm}$ (IR). [15]

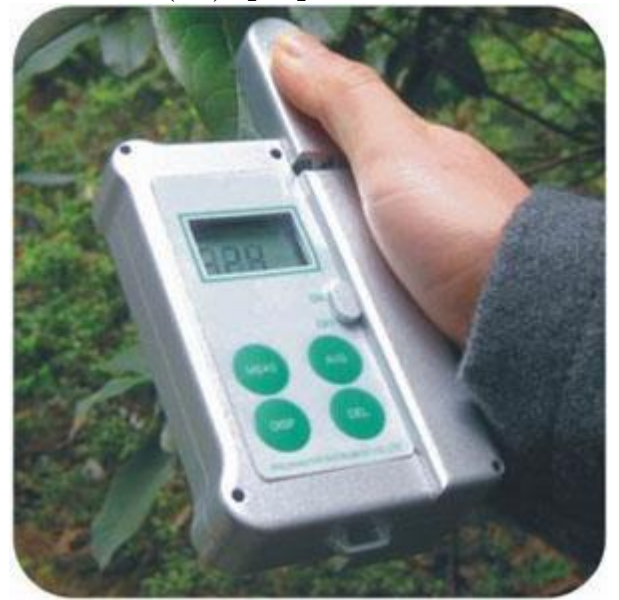

Figure 3. Chlorophyll Meter SPAD and HNT

$\square$ CropScan - portable device for measuring the incidence index and the reflected radiation of the foliar shell at 8 wavelengths.(Figure 4) 


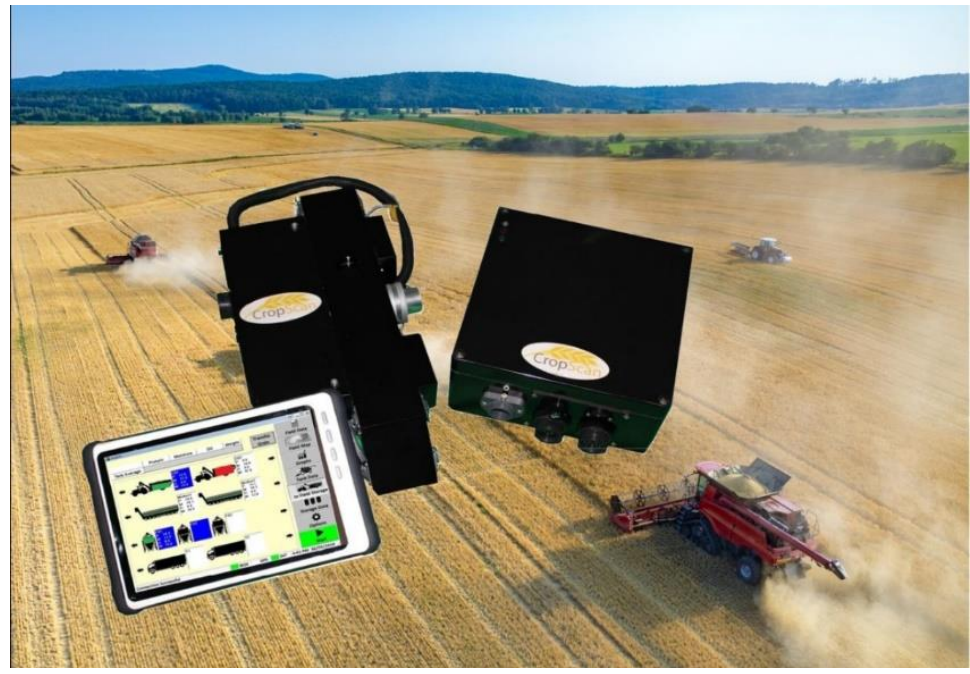

Figure 4. CropScan Device

-LCi Portable Photosynthesis System-portable (Figure 5) non-invasive device for determining photosynthesis, in real time, by measuring the parameters:

-leaf temperature;

-atmospheric pressure;

-active photosynthetic rate

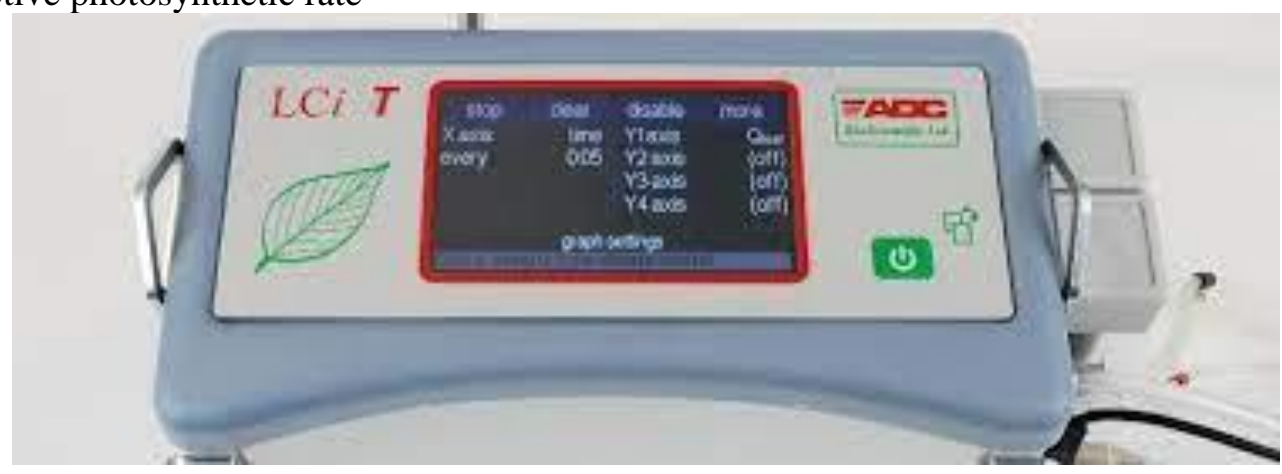

Figure 5. LCi Portable Photosynthesis System

Precision agriculture uses interactive systems, which include remote sensing, computer systems, digital cartographic data, software and applications in the fields of SIG/GIS, data and information agrometeorology, pedology, agrochemistry, phytotechnics, etc., GPS receivers mounted on agricultural equipment.

The space component, offered elements that come from GPS and GLONASS positioning satellites and that provide accurate location of sensors placed on agricultural equipment, as well as from remote sensing satellites, which provide the appropriate imaging support to multispectral analysis of phenological phases (phenophases) related to the evolution of plants in culture. [3]

The AGRI4CAST (Figure 6) system has been developed and is running in order to ensure the production forecasts of crops at European level in a timely manner. This system is capable of monitoring the evolution of annual crops (cereals, oil, protein crops, sugar beet, potatoes, pastures, rice) including the short-term effects of meteorological phenomena on yields, crops and can provide annual forecasts of European crop yields 

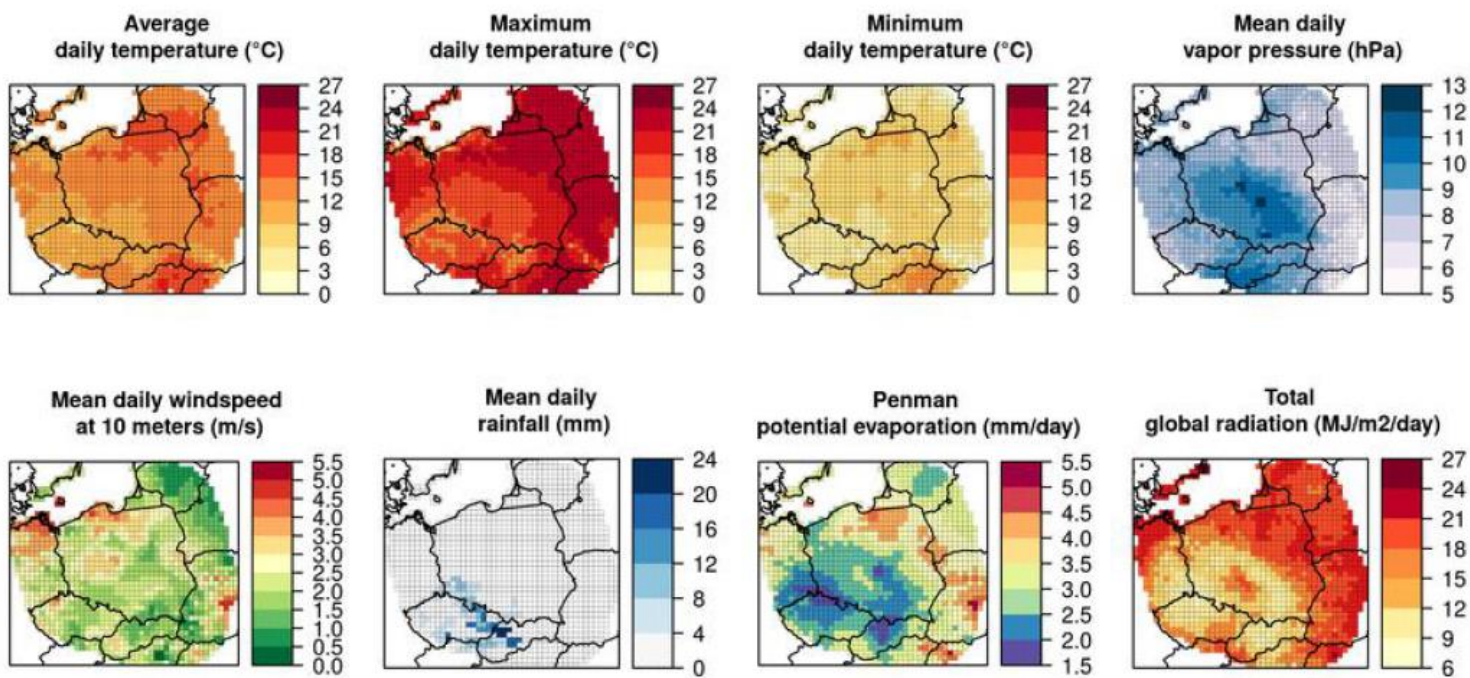

Figure 6 Examples of AGRI4CAST interpolated meteorological data [17]

The MATRIXTM 570G system (Figure 7) is a system for guiding the machine and measuring the farm surfaces. This system is made of the following components:

This system is made of the following components:

- Console

The Matrix $570 \mathrm{~g}$ is designed to operate in typical agricultural operating conditions. A hermetic casing combined with rubber caps for all connectors provides protection against dust

- Room "Real View"

The camera TeeJet Technologies RealView captures images to display on the device screen. The camera can be positioned forwards to allow RealView orientation over video, or it can be positioned to view other operational aspects of the equipment. The camera is equipped with a flexible support, sun guards and infrared lighting, which allows clear video even in low light conditions.

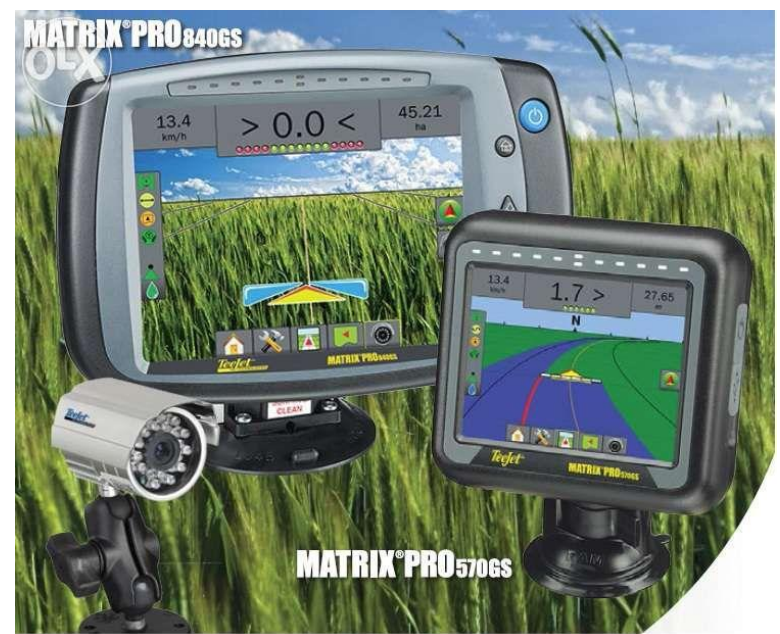

Figure 7- MATRIX Device 


\section{Conclusions}

The requirements of modern agriculture are related to high productivity and efficiency. The reduction of costs, the reduction of working time and the security of control over agricultural activities in their globality are the essential factors of profitability and competitiveness, both internally and externally.

GPS technology used in agriculture helps to maximize productivity, better control over input costs (herbicides, plant protection products, chemical fertilizers, seeds, fuel, etc.) and optimize profit.

With the GPS systems there is no longer a need for milestones to mark the directions on the ground, and this causes a decrease in labour costs.

Operations of applying chemicals are done precisely, thereby eliminating overlap errors. This translates into an economy of fuel and inputs, since the rows are parallel, regardless of their shape (straight, curved, round, etc.).

The use of satellite guidance systems achieves not only a saving of inputs, but also of time.

The systems for tracking the agricultural fleet allow the location in real time or according to a history, of the agricultural machines and of the employees who use them, from any computer or phone connected to the Internet.

Reports on working time and fuel consumption are generated. Fuel consumption is monitored by a catcher installed in the tank of the machine; in case of exceeding a consumption threshold, an SMS will be sent to the predetermined persons.

\section{References}

[1] $* * *$-http://www.esri.com

[2] ***-http://www.arcgis.ro

[3] ***-http://gps-agricultura.com/

[4] ***-http://www.affaires-roumanie.ro

[5] ***-http://www.teejet.com

[6] Curs ESRI Romania: ArcGIS Desktop I - Getting started with ArcGIS

[7] Curs ESRI Romania: ArcGIS Desktop II - Tools and Functionality

[8] Curs ESRI Romania: ArcGIS Desktop III - Performing Analysis with ArcGIS Desktop

[9] Stefan Ghimisi, Innovative models for sustainable agriculture Journal of Research and Innovation for Sustainable Society (JRISS), Nr 2/2020, ISSN: 2668-0416, pag.32-37, DOI: 10.33727/JRISS.2020.2.5:32-36

[10] Stefan Ghimisi, Ecological lubricants utilization, Fiabilitate si Durabilitate - Fiability \& Durability No 2/ 2020, ISSN-L 1844-640x, ISSN 2344-3669, p.17-25

[11] Mihail Dumitru, 2000 -Cod de bune practici, Editura Vox]

[12] ***-https://ro.scribd.com/doc/268300342/Mediul-Si-Sistemele-de-Agricultura)

[13] Olteanu, Gh., I.M. Oltean, Ioana Oltean, 2002, Agricultura de precizie Ed.Ceres, Bucureşti, .

[14] ***-www.kress-andtechnik.de/wEnglisch/produkte/pdf_verzeichnis/

[15] (Arslan,S and T.S.Colvin.2002.Grain yield mapping:yield sensing,yield reconstruction and errors.Precision agriculture)

[16] ***-http://www.gazetadeagricultura.info/afaceri-agricole/617-management agricol/17710agricultura-de-precizie-software-management-ferma.html

[17] ***-https://www.researchgate.net/figure/Examples-of-AGRI4CAST-Interpolated-

Meteorological-Data-on-25-April-2011-based-on-the_303946790 